\section{Statin Intolerance} and Vitamin D Supplementation:

\section{Sunny, but a Few Clouds Remain...}

\section{Dear Editor,}

We read with interest the article by Khayznikov et al., regarding the resolution of statin intolerance with vitamin D repletion. ${ }^{[1]}$ We too have tried this strategy among a similarly statin intolerant population (median - three previous statins) and believe vitamin D supplementation plays a role in treating certain individuals. Our results demonstrated that vitamin D repletion to $>30 \mathrm{ng} / \mathrm{ml}$, allowed $53 \%(18 / 34)$ of the intolerant patients to utilize some form of alternative or daily statin dosing or a higher dose among those receiving a statin but experiencing tolerable symptoms, for at least four months (mean follow up $8.5+4.4$ months). Our findings are encouraging but well below the $88-95 \%$ statin tolerability rates reported in the present study.

Directly comparing study populations and results is not feasible; however, one potential explanation for response differences may be the vitamin D level achieved. For instance, the vitamin D levels among those tolerating the statin rechallenge in our group was $44 \mathrm{ng} / \mathrm{ml}$ compared to $53-55 \mathrm{ng} / \mathrm{ml}$ in the current report, suggesting that perhaps our vitamin D repletion was incomplete, despite each group falling within the range suggested by the Endocrine Society. ${ }^{[2]}$

Another factor that we believe played a prominent role in the resolution of myalgic symptoms in the current study was the predominant utilization of rosuvastatin. The authors recognize that rosuvastatin is less frequently associated with myotoxicity; however, this should not be minimized. In fact, the same research center performed a similar study, and determined that the vast majority of previously statin intolerant subjects reported no adverse effects when rechallenged with rosuvastatin 5-10 $\mathrm{mg}$ daily. ${ }^{[3]}$

Lastly, we agree with the authors that an optimal study evaluating statin intolerance would be blinded and placebo-controlled, given the subjective nature of most myotoxicity. In fact, this design was recently utilized to assess various lipid-altering agents, including the investigational proprotein convertase subtilisin/kexin type 9 (PCSK9) inhibitors, among subjects unable to tolerate two or more different statins because of unexplained muscle-related symptoms. ${ }^{[4]}$ After successful completion of a four-week single-blind placebo run-in period, subjects were randomized in a double-blind manner to a PCSK9 injection $Q$ two weeks + oral placebo daily, ezetimibe $10 \mathrm{mg}$ daily + placebo injection $\mathrm{Q}$ two weeks, or atorvastatin $20 \mathrm{mg}$ daily + placebo injection $Q$ two weeks, for 24 weeks. Such a study design provided novel, insightful, and revealing findings with regard to statin intolerance. For example, the trial demonstrated that $6.9 \%$ of subjects were excluded from randomization due to muscle-related adverse events during the placebo run-in period. Further, $75 \%$ of the previously intolerant patients tolerated the atorvastatin $20 \mathrm{mg}$ daily for the duration of the 24-week study period. Such results strongly highlight the subjectivity of statin intolerance and the major influence of a placebo effect in many patients.

Statin intolerance, especially among patients with previous sensitivity to multiple agents, is a complex and poorly understood issue that remains a clinical challenge. In the present study, vitamin D repletion likely improved muscle function and resolved symptoms in some patients. However, the vitamin D supplementation may have also provided a placebo effect, while the utilization of rosuvastatin further enhanced response.

Financial support and sponsorship

Nil.

\section{Conflicts of interest}

There are no conflicts of interest.

James M Backes, Janelle F Ruisinger, Brian J Barnes ${ }^{1}$, Patrick M Moriarty ${ }^{2}$ Departments of Pharmacy Practice and Medicine and ${ }^{2}$ Medicine, Kansas University Medical Center and the University of Kansas School of Pharmacy, Kansas, 'Department of Pharmacy Practice, University of Kansas School of Pharmacy, Kansas, United States E-mail: jbackes@kumc.edu

\footnotetext{
This is an open access article distributed under the terms of the Creative Commons Attribution-NonCommercial-ShareAlike 3.0 License, which allows others to remix, tweak, and build upon the work non-commercially, as long as the author is credited and the new creations are licensed under the identical terms.
}

For reprints contact: reprints@medknow.com

How to cite this article: Backes JM, Ruisinger JF, Barnes BJ, Moriarty PM. Statin intolerance and vitamin D supplementation: Sunny, but a few clouds remain... North Am J Med Sci 2015;7:337-8. 


\section{References}

1. Khayznikov M, Hemachrandra K, Pandit R, Kumar A, Wang P, Glueck CJ. Statin Intolerance Because of Myalgia, Myositis, Myopathy, or Myonecrosis Can in Most Cases be Safely Resolved by Vitamin D Supplementation. N Am J Med Sci 2015;7:86-93.

2. Pludowski P, Holick MF, Pilz S, Wagner CL, Hollis BW, Grant WB, et al. Vitamin D effects on musculoskeletal health, immunity, autoimmunity, cardiovascular disease, cancer, fertility, pregnancy, dementia and mortality - A review of recent evidence. Autoimmun Rev 2013;12:976-89.

3. Glueck CJ, Aregawi D, Agloria M, Khalil Q, Winiarska M, Munjal J, et al. Rosuvastatin 5 and $10 \mathrm{mg} / \mathrm{d}$ : A pilot study of the effects in hypercholesterolemic adults unable to tolerate other statins and reach LDL cholesterol goals with nonstatin lipid-lowering therapies. Clin Ther 2006;28:933-42.
4. Moriarty PM, Thompson PD, Cannon CP, Guyton JR, Bergeron J, Zieve FJ, et al. ODYSSEY ALTERNATIVE: Efficacy and Safety of the Proprotein Convertase Subtilisin/ kexin Type 9 Monoclonal Antibody, Alirocumab, versus Ezetimibe, in Patients with Statin Intolerance as Defined by a Placebo Run-in and Statin Rechallenge Arm. American Heart Association Scientific Sessions 2014; 2014 November 17 ${ }^{\text {th }}, 2014$.

\begin{tabular}{|l|l|}
\hline \multicolumn{2}{|c|}{ Access this article online } \\
\hline Quick Response Code: & Website: \\
\hline & www.najms.org \\
\hline & \\
\hline
\end{tabular}

